\title{
Evolução histórica dos utensílios empregados para alimentar lactentes não amamentados
}

\author{
Historical evolution of utensils used to feed non breastfed infants
}

Silvia Diez Castilho ${ }^{1}$

Antonio de Azevedo Barros Filho ${ }^{2}$

M onize Cocetti ${ }^{3}$

${ }^{1}$ FaculdadedeM edicina, Pontifícia Universidade Católica de Campinas. Av. John Boyd Dunlop s/n, Jardim I paussurama. 13059-900 Campinas SP. sdiezcast@puccampinas.edu.br ${ }^{2}$ Departamento de Pediatria, Faculdade de Ciências M édicas, UNICAMP.

${ }^{3}$ Faculdade deNutrição, Pontifícia Universidade Católica deCampinas.
Abstract Theobjective of this article is to describe the utensils used throughout history to feed non breastfed infants. The method used was articlere view, reference search on the M ED LINE, LILACS and SciELO databasesfrom 1966 to 2007 and documental analysis based on data from the internet, encyclopedias, art and history books, and museums. Utensils manufactured in a variety of materials and shapes, depending on availability, purchasing power and culture have been used since early history to feed babies who for different reasons were not breastfed. M any objects coexisted at the sametimeand place, others at distant sites and times. $\mathrm{N}$ ew alternatives have been accepted without evidence to prove or point toward the benefits of the change. Some of these alternatives were adopted again, even if infant mortality was high at the time in which they were used at first. In the beginning of the 20th century, bottles became conic-cylindrical. Technology brought about progress as to improve hygiene and enable contamination control. Glass gaveway to plastic, and rubber nipples to silicone ones, but the bottle as we know it today is still the same of a 100 years ago. Key words Breast feeding, Weaning, Bottle feeding, History
Resumo 0 objetivo desse artigo de revisão édescrever os utensílios em pregados ao longo da história para alimentar lactentes não amamentados. O levantamento bibliográfico foi realizado nas bases de dados M ED LIN E, LILACS eSciELO, de1966 a 2007. Para a análise documental, foram processadas buscas na I nternet, em enciclopédias, livros de arte, história e museus. U tensílios manufaturados com materiais e formas variadas, dependendo da disponibilidade, poder aquisitivo e cultura, foram empregados desde os primórdios da história para alimentar bebês que, por diferentes motivos, deixaram de ser amamentados. M uitos objetos coexistiram na mesma época e local, outros em tempos e pontos geográficos distantes. A aceitação de uma nova alternativa ocorria sem evidência que comprovasse ou apontasse para os benefícios da mudança. Alguns utensílios voltaram a ser empregados embora a mortalidade infantil fosse elevada à época em que foram utilizados. No início do século XX, as mamadeiras assumiram a forma cilíndrica cônica. A tecnologia trouxe avanços no sentido de melhorar a higienização e possi bilitar o controle da contaminação. 0 vidro deu lugar ao plástico e os bicos de borracha, aos de silicone, mas a mamadeira, como a conhecemos hoje, éa mesma de cem anos atrás. Palavras-chave Amamentação, Desmame, Alimentação artificial, História 
Introdução

O leite materno éo melhor alimento para o crescimento e desenvolvimento saudável dos lactentes ${ }^{1}$. M as, apesar das inúmeras vantagens da amamentação para a saúde da criança e da mãe, a economia que ela representa para a família e para o Estado, diferentes interesses sociais e econômicos, muitas vezes divulgados como avanços científicos e tecnológicos, têm levado ao desmame ${ }^{2-5}$.

Desde os primórdios da história, quando 0 leitehumano era aúnica chance desobrevida para os bebês, o homem vem buscando soluções alternativas para responder à demanda de mulhe res que, por opção, necessidade ou imposição, deixam de amamentar seusfilhos ${ }^{6}$. Inicialmente, recorreu às amas, depois ao leite animal e a outros alimentos, que tiveram que ser administrados através de objetos especial mente desenvolvidos para esta finalidade.

A presenterevisão tem como objetivo descrever os diferentes utensílios empregados ao longo da história para alimentar lactentes não amamentados.

\section{Método}

Trata-se de artigo de revisão bibliográfica e análisedocumental. 0 levantamento bibliográfico foi realizado nas bases de dados M EDLINE, LILACS e SciELO, abrangendo o período entre 1966 e 2007. Para a análise documental, foram processadas buscas na Internet, em enciclopédias, livros de arte, história e museus. Como fontes de dados, foram consideradas a literatura científica, a opinião e recomendação de profissionais, os costumes de diferentes culturas relatados na literatura leiga, a mitologia, peças expostas em museus, desenhos encontrados em cavernas, pinturas em paredes de ruínas, achados arqueológicos de múmias de crianças enterradas com seus pertences, relatos bíblicos, textos de filósofos e obras de arte que retratam o cotidiano.

\section{Resultados ediscussão}

Existem evidências de que, há milhares de anos, bebês têm sido alimentados artificialmente por meio de utensílios (vasilhas ebicos). A aceitação de uma nova alternativa frequentemente ocorria sem evidência empírica que comprovasse ou apontasse para os benefícios da substituição. Claro que essas mudanças não ocorreram de forma linear, como será aqui apresentado por questões didáticas. Muitos objetos coexistiram na mesma época e local, outros em tempos e pontos geográficos distantes. Algumas lacunas em relação a determinadas regiões ou épocas também podem ser percebidas por falta de informações disponíveis.

A necessidade de suplementar o leitematerno acompanha o homem desde 0 início de sua história. Em tempos remotos, quando por razões externas à sua vontade a mãe deixava de amamentar seu filho, outra mulher a substituía, para assegurar a sobrevivência da espécie?

Através da mitologia, a humanidade tem recontado histórias, que determinadas culturas acreditavam ser verdadeiras, ou usado eventos e caracteres sobrenaturais para explicar o universo e a humanidade. Dois episódios chamam a atenção, pois tratam de bebês que teriam sobrevivido às custas de terem sido alimentados por animais. Segundo a mitologia romana, Rômulo e Remo foram abandonados em uma cesta no rio Tibre e achados por uma loba, que os amamentou junto com suas crias; no lugar onde foram encontrados, eles teriam fundado, mais tarde, a cidade de Roma ${ }^{8}$. Já a mitologia grega relata que Zeus foi alimentado por uma cabra (Amaltéia), após também ter sido abandonado por sua mãe, que temia que o pai o devorasse para não ser, um dia, destronado ${ }^{9}$. A arte cuidou de imortalizar estes dois episódios em esculturas e pinturas espalhadas por diversas cidades e museus, principalmente da Europa.

No período pré histórico, particularmenteno período Paleolítico Superior (35.000-10.000 a.C.), o ser humano tinha uma vida nômade; catava e caçava para sobreviver. A linguagem era rudimentar, baseada em sons sem elaboração de palavras ${ }^{10}$. U ma forma de comunicação era através da arterupestre. Pinturas em cavernas focam elementos do meio ambiente demonstrando as ocupações da época. Retratam manadas em planícies e vales, que eram o alvo desua caça. Esculturas com proporções exageradas representam mulheres em todos os estágios da vida (puberdade, gravidez, parto e velhice). N esse período remoto, amamentar era instintivo e não sofria influência cultural, pois esta apenas começava a se delinear ${ }^{10}$. A mãe que não podia amamentar condenava 0 filho à morte, a menos que outra mulher a substituísse; não havia outra opção. Passando da fase da pedra lascada para a pedra polida, o homem foi desenvolvendo aos poucos soluções práticas para os problemas do seu cotidiano e inventando objetos a partir de suas ne- 
cessidades. No período Neolítico (8.000-4.000 a.C.), as pessoas começaram a se estabelecer em pequenas comunidades agrícolas. O bjetos, desenhos e esculturas encontrados, que datam deste período, apontam para as necessidades e crenças da época ${ }^{10}$. A arte rupestre mostra pastores conduzindo gado. Animais como os auroques, ancestrais dos atuais bovinos, começaram a ser domesticados, mas eram agressivos e precisavam ser mantidos longe das plantações para que elas não fossem pisoteadas. M esmo as fêmeas, de menor porte, eram agressivas e é pouco provável que tenham se deixado ordenhar com facilidade. Utensílios confeccionados em cerâmica, nesta época, foram encontrados no Japão (6.000 a.C.) e têm forma cônica, podendo ter sido usados como $\operatorname{copos}^{10}$. Alternativas para a suplementação ou substituição do leite materno, neste período, ficam restritas a especulações, mas acredita-se que, com a domesticação de bovinos, ovinos e caprinos, muitas crianças sobreviveram graças a serem alimentadas com leiteanimal oferecido em vasilhas ou colocadas para mamar no ubre de animais ${ }^{10-12}$.

A escrita foi desenvolvida pelos sumérios entre 4.000 e 3.000 a.C., mas coube aos assírios e babilônios expandi-la, permitindo o registro sobre os hábitos de cada povo ${ }^{13}$.

As primeiras evidências da criatividade humana no sentido de administrar alimento aos bebês datam de 4.000 a $2.000 \mathrm{aC}^{12,14}$. Os mais antigos são feitos de barro em forma de animais ou de vasos (jarros de vinho). Em comum, eles apresentam um orifício superior, por onde 0 alimento era introduzido, e um apêndice lateral, como um bico perfurado, que era introduzido na boca do bebê para que o alimento fosse sugado (Figura 1) ${ }^{14}$.

Antes da era cristã, babilônios (2.500 a.C.) e egípcios (1.500 a.C.) tinham como norma amamentar os filhos por um período de dois ou três anos. Para esses povos, como para o povo hebreu, cuidar dos filhos e amamentar eram dádivas divinas $^{11}$. N esta mesma época, no entanto, existem referências à alternativa das amas de leite ${ }^{11,15}$.

$\mathrm{Na}$ Bíblia, encontramos relatos sobre os costumes do povo hebreu. Algumas passagens referem-se à amamentação ou às amas, que substituíam a mãe verdadeira quando esta por algum motivo não podia amamentar. Dois mil anos antes de Cristo, Sara amamentou I saque (Gênesis $21: 7$ ). M oisés (1.500 a.C.) foi amamentado pela mãe atéos três meses edepois entregue, pela filha do faraó, para ser "criado por uma ama" (Êxodos 2:1-10). Não há menção da idade que ele tinha quando foi devolvido à filha do faraó, mas sabe-se que as crianças eram consideradas "criadas" quando deixavam de ser amamentadas; e o texto diz que "ele já era grande". Estudiosos acreditam que M oisés passou tempo suficiente com seu povo para conhecer os costumes hebraicos. Samuel, que nasceu por volta de 1.000 a.C., foi "criado ao peito" pela mãe (I Samuel 1:23) e Joás, por volta de 800 a.C., foi "criado por uma ama", para fugir à fúria de Atalaia, que tentava destruir toda a descendência real (2 Reis 11:13) 16,17. O utras passagens, como Gênesis 18:1, Juízes 5:25 e Salmos 55:21, mostram que o leite e derivados eram usados como alimento ${ }^{12,17}$. Embora, na Bíblia, não existam referências diretas de como os bebês eram alimentados quando por algum motivo deixavam de ser amamentados, pode-se imaginar que havia a opção de receber leiteanimal.

Vasos egípcios, de 1.500 a.C., mostram muIheres segurando ou amamentando bebês, ou portando chifres com a ponta escavada em forma de colher com a qual alimentam crianças ${ }^{11}$. Alguns acreditam que objetos antropomórficos eram usados para administrar leite animal às crianças. Um destes vasos ( 1.400 a.C.) em forma de mulher segurando um dos seios, segundo Fildes, parece remeter à possibilidade de que continha leite materno ordenhado ${ }^{11}$. O utros estudiosos, no entanto, defendem a tese de que estas formas poderiam representar o desejo dequeseu conteúdo tivesse os poderes mágicos do leite materno, no sentido de proteger a criança que dele se al imentasse ${ }^{11}$.

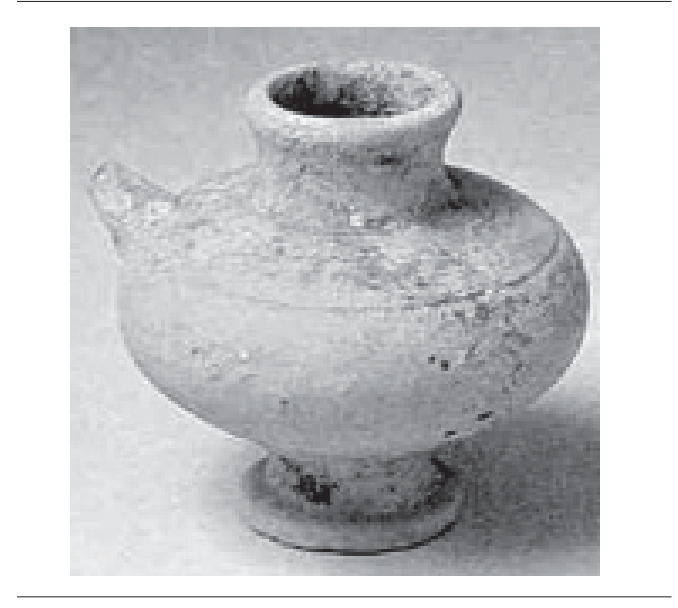

Figura 1. Vaso com apêndice lateral perfurado. Chipre, 2.000 a.C.

Fonte: The history of the feeding bottle - the early feeders (http://www.babybottle-museum.co.uk/early.htm) 
A literatura médica da Índia Antiga (1.500 a 800 a.C.) relata que os recém-nascidos deveriam ser alimentados com uma mistura de mel, manteiga e fol has nos primeiros quatro dias. A regra era amamentar, mas caso o leite materno não descesse, uma ama tomaria o lugar da mãe. $\mathrm{Na}$ ausência de leite humano, as famílias eram orientadas a dar leite de vaca ou cabra para o bebê, mas não existem referências sobre modo de administração a ser usado: se direto do ubre do animal ou através de utensílios ${ }^{11}$.

Túmulos de pessoas que viveram há muitos séculos revelam seus hábitos e costumes, pois era comum enterrar os mortos com seus pertences. Em 1978, no noroeste da China foram descobertas as múmias de Cherchen, que datam de três mil anos (1.000 a.C.). Para espanto dos arqueólogos, corpos, roupas e demais objetos estavam em perfeito estado de conservação. Ao lado de um bebê de três meses (com traços ocidentais), foi encontrada uma "mamadeira", feita de ubre de ovelha. 0 objeto revela uma outra forma utilizada na época para alimentar as crianças que porventura não estivessem sendo amamentadas ${ }^{18}$. Este é um achado incomum e precioso, uma vez que o material orgânico costuma se deteriorar com o passar do tempo.

Outras evidências do uso de métodos alternativos para alimentar crianças pequenas foram encontradas em desenhos pintados nas paredes das ruínas de N ineveh (890 a.C.), às margens do rio Tigre. Estes desenhos mostram a rainha de $\mathrm{N}$ ineveh, divindade em forma de uma vaca, amamentando o pequeno rei da Assíria, Ashurbanipal, e mulheres alimentando bebês maiores, com um vaso em uma das mãos e na outra um utensílio semel hante a uma colher. Gravações relatam o fato e muitos crêem que esta seja uma possível referência ao aleitamento artificial com leite de vaca $^{11}$.

H ipócrates (460-377 a.C.), médico grego considerado o "pai da medicina", foi um dos pioneiros em reconhecer quea amamentação diminuía a mortalidadeinfantil, por ser uma "dieta higiênica" $^{15}$. M esmo assim, amamentar não era um costume muito popular nessa época entre os gregos. Enquanto as pessoas mais abastadas recorriam ao aluguel de amas de leite, as mais simples buscavam outras formas para alimentar as crianças não amamentadas ${ }^{15}$. No Museu de Artes de Cleveland, encontra-se exposta uma peça em terra$\operatorname{cota}(450$ a.C.), semel hante a um cofrinho de barro em forma de um porquinho, que servia para as mães gregas alimentarem as crianças com uma mistura de vinho e me ${ }^{14}$. A referência do queera oferecido neste tipo de recipiente indica que os bebês também recebiam outros alimentos para suplementar ou substituir o leite humano. Muitos outros objetos usados com a mesma finalidade foram encontrados em sítios arqueológicos babilônicos, gregos, romanos, etruscos e judaicos, particularmente em túmulos de crianças ${ }^{11,14}$. M édicos contemporâneos ( 100 a 200 d.C.), nascidos na Grécia, divergiam quanto às orientações sobre a amamentação. Enquanto Galeno indicava que o recém-nascido fosse colocado para sugar o seio materno imediatamente após o parto, Sorano acreditava que o leite humano só podia ser oferecido à criança dois dias após o nascimento. N esteperíodo, o bebêficava em jejum ou recebia uma mistura de leite de cabra com mel. Até que o leite da mãe passasse a ser "considerado adequado", o que segundo ele ocorria por volta do vigésimo dia, a criança deveria ser amamentada por outra mulher ${ }^{11,12}$. Esta conduta muito provavelmentedificultava o estabelecimento da amamentação pela mãe, empobrecia o vínculo mãefilho elevava ao desmame precoce.

Em Roma, filósofos como Plínio (23 a 79 d.C.) e Plutarco (50 a 120 d.C.) eram a favor da amamentação, recomendando sua prática para todas as classes sociais. Suas falas eram contra a compra de escravas ou 0 aluguel de amas pelas classes mais abastadas ${ }^{11}$. Galeno e Sorano, embora gregos, mudaram-se para Roma e influenciaram com suas idéias e divergências a sociedade de então ${ }^{11,12}$.

Por volta de 300 a 250 a.C, os egípcios desenvolveram a habilidade de produzir 0 vidro. Coube, no entanto, aos romanos aperfeiçoar essa técnica de modo a remover as impurezas da areia e produzir vidro transparente. Isso ocorreu no início da era cristã. Alguns utensílios fabricados com vidro nessa época se assemelham a vasos, com pescoço longo e fino, e têm um pequeno apêndice lateral com um furo no meio, na porção mais arredonda, por onde a criança sugava o seu conteúdo ${ }^{19}$. 0 interessante éque o uso desse material, para a manufatura de vasilhas, logo perdeu a popularidade e só voltou a ter aceitação, para esse fim, em meados do século XIX 12,14,19. 0 barro ea argila (cerâmica) continuaram a ser os materiais mais utilizados por um longo tempo.

As antigas leis romanas admitiam o infanticídio e o abandono de crianças, particularmente as bastardas e as do sexo feminino. As cidades possuíam lugares específicos para que os bebês indesejados fossem abandonados. Alguns podiam ser recolhidos para setornarem escravos, mas 
a maioria morria. Essa situação determinou, com o tempo, a busca de uma forma que permitisse a sobrevivência desses bebês. 0 primeiro hospital para crianças abandonadas surgiu em Milão no ano de 787 d.C. ${ }^{11}$. Amas de leite eram pagas para amamentá-las no próprio hospital ou para as levarem para suas casas até que fossem desmamadas. Como ganhavam pouco, essa tarefa nem sempre era cumprida e, para que sobrevivessem, as crianças acabavam sendo alimentadas de outra forma, por meio de utensílios ${ }^{11}$.

Em estudo que compara as recomendações médicas na China eno 0 cidente, nosúltimosdois mil anos, os autores concluíram que os chineses sempre estiveram mais próximos aos conceitos e orientações atualmente aceitos ${ }^{20}$. Enquanto a medicina ocidental ocupou-seem advertir as mães sobre a inadequação do leite materno, especialmente nas primeiras semanas de vida (conceito quepermaneceu inquestionável até1700), dificultando 0 estabelecimento e desestimulando a amamentação, escritos chineses descrevem que o recém-nascido devia ser colocado ao seio imediatamente após o parto, pois o leite materno possui desde o início as mel hores qualidades para o crescimento edesenvolvimento do lactente ${ }^{20}$.

A medicina e a filosofia conhecidas no Islã (900 d.C.) também foram influenciadas pelos gregos, principalmente, através de Avicena ( 980 a 1.037 d.C.). Eleadvertia contra a escolha deamas. Maomé (570 a 632 d.C.), anos antes, já havia condenado essa prática por achar que as crianças poderiam ser afetadas negativamente pela saúde e pelo caráter da ama ${ }^{11}$. Ainda hoje, as leis islâmicas exigem que a mãe amamente seus fiIhos por dois anos, "pois Allah reconhece que 0 leite materno éo al imento mais saudável para os bebês"21. U ma ama só pode ser chamada caso a mãe não possa amamentar.

Fildes refere que fontes não médicas deixam claro que, principalmente na Europa O cidental, desde início do segundo milênio (século XI), muitas mulheres saudáveis de famílias nobres pagavam para que amas amamentassem seus fiIhos $^{11}$. Com o tempo, essa prática se tornou cada vez mais difundida, sendo utilizada também por famílias de artesãos e comerciantes. Muitas vezes, as crianças eram amamentadas pela mãe e pela ama demodo intermitente, permitindo que, se a ama ficasse doente, engravidasse ou morresse, a mãe pudesse al imentar o filho até que outra ama fosse encontrada. Inicialmente, as amas eram admitidas em casa, sendo supervisionadas pela mãe, e eram bem pagas se comparadas a outras empregadas. As que aceitassem levar as crianças para suas casas recebiam ainda melhores salários. A escultura da M adonna del latte (Nino Pisano, 1350) retrata a amamentação, modo mais comum de alimentar os bebês nesta época. $\mathrm{N}$ a verdade, não fica claro o motivo pelo qual as mulheres não queriam amamentar, pois tinham boa saúde e as roupas eram adequadas, diferentes das usadas em outras épocas, quando os espartilhos dificultavam dar o seio com frequência à criança ${ }^{11}$.

Durante a Idade M édia (séculos V a XV), registros mostram quena Europa as crianças recebiam alimentos por meio de chifres de animais, aos quais eram atados pedaços de couro ou ubre de animais, preenchidos com pedaços de pano ou esponja ${ }^{12}$. Berços da época tinham um suporte que mantinha o utensílio na al tura da boca da criança ${ }^{11}$. Essa prática foi bastante difundida, provavelmente pela facilidade em adquirir os chifres e pelo baixo custo do material. Após o descobrimento da América, observou-se que os índios americanos também empregavam chifres para administrar alimentos para os bebês ${ }^{12,14,19}$. Outros recipientes, como frascos de madeira e couro, começaram a ser utilizados na Alemanha e na I tália por volta dos séculos XIII eXIV ${ }^{14}$.

Com o Renascimento (séculos XIV a XVI), a arte voltou a fornecer informações sobre hábitos comuns da época. Data de 1506 a primeira pintura em que aparece um bebêsegurando um objeto semelhantea uma chupeta- M adonna with Siskin, de Albrecht Durer ${ }^{22}$. Este quadro está exposto no Museu Estatal de Berlin. Essas "chupetas" foram descritas em 1873 por Jamison em seu livro Ropes of Sand. Elas eram feitas de pedaços de pano, amarrados como trouxinhas, e continham pão, grãos, carne, peixe, gordura, ou pedaços de esponja embebida em mel. Serviam não só para acalmar a criança, mastambém para nutri-la. Nos séculos XVIII e XIX, esta alternativa foi bastante criticada pelos médicos, por ser anti-higiênica e fonte da transmissão de doenças ${ }^{14}$.

Por volta de 1500, começaram a aparecer os primeiros livros impressos, o que facilitou, em parte, a disseminação de informações.

No século XVI, duranteuma epidemia desífilis na França, as crianças eram colocadas para mamar diretamente em animais ${ }^{11}$. Acreditava-se que este método aumentava as chances de sobrevida das crianças, infectadas ou abandonadas, se comparado com as que recebiam papinhas. Assim, mulas e cabras foram utilizadas, em hospitais e orfanatos da Europa, até o início do século $X X .{ }^{11}$ Ainda hoje, muitas crianças africanas sobrevivem mamando direto do ubre de animais. 
Durante o século XVII, os frascos de madeira e couro foram sendo gradativamente substituídos por vasilhames de estanho, em forma de canecas, que apresentavam um apêndice lateral (como os utilizados séculos antes de Cristo), e frascos com gargalo estreito com tampa rosqueada no topo, de onde saía um apêndice para ser sugado, muito semelhantes à mamadeira que conhecemos hoje, mas com um bico duro também de estanho (Figura 2). Estes objetos, como os primeiros frascos de cerâmica e barro de sé culos antes de Cristo, eram difíceis de serem limpos, o que, somado à frequente contaminação do leite, determinava altas taxas de mortalidade infanti| ${ }^{11,14,19}$.

Entre os séculos XVII e XIX, apareceram os pap boats. N estes utensílios, os bebês recebiam leite ou papinhas, feitas de uma mistura de água ou leite com pão ou farinha. Estas papinhas podiam ser enriquecidas com açúcar, vinho, cerveja ou mel, e eram conhecidas pelo nome de "panadas". Os pap boats eram recipientes pequenos, rasos, abertos, geralmente ovais, com uma porção afilada em uma das pontas, que permitia que o alimento fosse despejado aos poucos na boca da criança (Figura 3). Eles foram manufaturados em diversos materiais, variando com a épo-

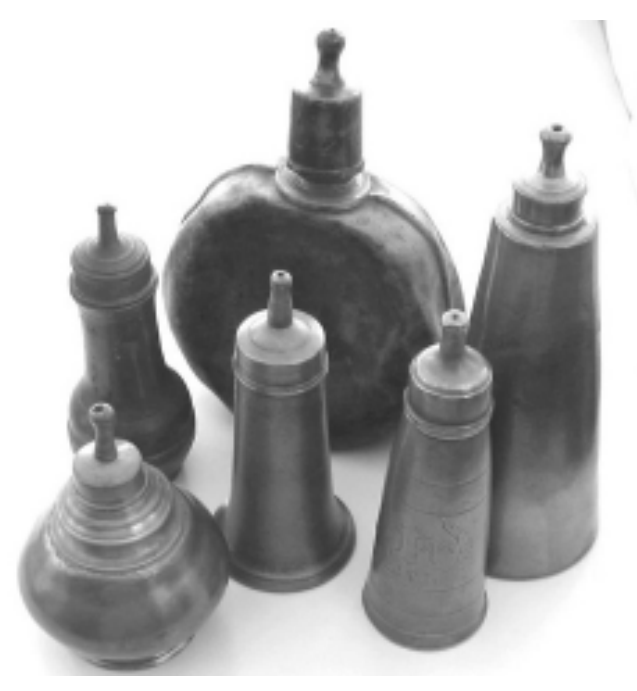

Figura 2. Garrafas de estanho com rosca e bico, também de estanho; séculos XVII a XVIII.

Fonte: Jinny's collection

(http://www.babybottle-museum.co.uk/collections_2.htm) ca e com o poder aquisitivo - de estanho a prata, de cerâmica a porcelana, lisa ou decorada. Embora sua forma facilitasse a higienização, crianças alimentadas desta maneira acabavam ficando doentes por não receberem nutrientes em qualidade e quantidade necessárias ou pelo fato das papas serem feitas com alimentos e utensílios contaminados e mantidas quentes em fogões, para serem administradas a qualquer momento ${ }^{11,12,14,19}$. À medida que as crianças cresciam, elas continuavam recebendo alimentos nos pap boats e embora as papas fossem mais espessas, a dieta raramente se tornava mais atrativa. N esta mesma época, uma variação dos pap boats servia não só para alimentar crianças como também para alimentar pessoas acamadas. Trata-se dos feeding cups, feitos de cerâmica ou porcelana, que tinham a mesma forma dos pap boats, mas também uma alça e parte das superfície afilada coberta, assumindo forma parecida com a de uma molheira ${ }^{11,12,14,19}$. O fechamento de parte da superfície reintroduzia novamentea dificuldade de higienização. Paulatinamente, estes objetos se transformaram em bubby pots, com formas arredondadas, uma abertura estreita na porção superior e um pequeno apêndice lateral com um furo, para a criança sugar o alimento, prejudicando ainda mais sua limpeza. Este recipientes eram parecidos com os utilizados dois mil anos antes de Cristo ${ }^{12,14}$. Outras variedades eram os sucking pots, semel hantes a bules de chá, cujo bico era preenchido por um pedaço de pano ou amar-

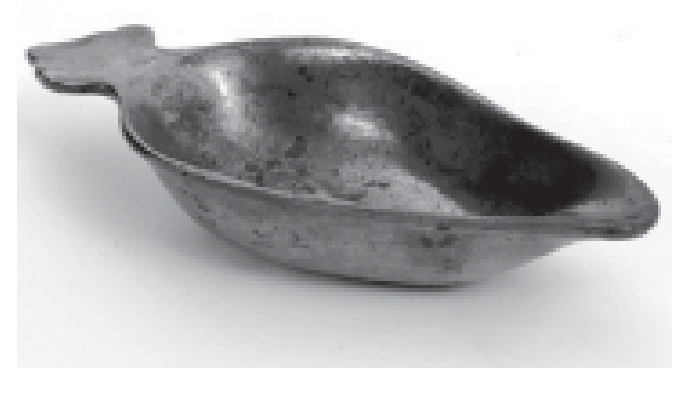

Figura 3. Pap-boat de estanho; séculos XVII a XIX.

Fonte: http://cgi.ebay.com/ws/eBaylSAPI.dII?ViewI tem\&item $=150142703636 \&$ from M akeTrack=true\&ssPageN ame=VIP: watchlink:middle:us 
rado a um ubre de animal para que a criança sugasse 0 alimento, e os submarine infant feeders que tinham dois orifícios, um na ponta para ser sugado pela criança e um na parte superior por onde, usando o polegar, podia-se controlar o flu$x o$ de leite ${ }^{11,12,14,19}$. Sua forma era semel hanteà de uma lamparina. Em meados do século XIX, quando o vidro reapareceu, ele rapidamente substituiu os utensílios de estanho e porcelana ${ }^{12}$.

Nos séculos XVII eXVIII, na França, era comum as mães das classes média e alta enviarem, por opção, seus filhos para serem amamentados por amas no campo, com quem ficavam até os quatro anos ${ }^{23}$. Para a cultura e a sociedade da época, a criança era vista como um sinal do pecado, era pouco valorizada, sua morte era considerada um acontecimento banal e dar-Ihe carinho mostrava fraqueza. Além disso, a amamentação não era vista com bons olhos, pois as muIheres "privar-se-iam de um suco precioso necessário para sua conservação" e perderiam a saúde. Tal argumento era destituído de qualquer fundamento médico. Avós e parteiras desaconsel havam a amamentação, mas se a mãe quisesse mesmo amamentar, deveria esconder-se, o que prejudicaria sua vida social por um longo tempo. A opinião dos maridos também era contrária a esposa amamentar, pois ela prejudicava a sexualidade e restringia seu prazer ${ }^{23}$. N esta época, surgiram na Europa agências que recrutavam amas de leite. $A$ partir do final do século XVII einício do século XVIII, algumas mães que usavam este serviço começaram a rejeitar tal prática. Entre os fatores responsáveis por essa mudança estão a valorização do colostro, anteriormente reconhecido como inadequado, e a maior aceitabilidade da alimentação artificial por parte da sociedade e dos médicos ${ }^{11}$. Em meados do século XVIII, a Revolução Industrial, iniciada na Inglaterra, determinou a migração para centros urbanos e a mulher simples do campo, que estava acostumada a amamentar seus filhos e servir de ama para os filhos de famílias abastadas, passou a trabalhar na indústria. Esse episódio determinou o declínio da amamentação na Europa eo aumento da mortalidade infantil por diarréia e desnutrição ${ }^{24}$. A necessidade contribuiu tanto para a existência de inúmeras alternativas para administrar as "panadas" quanto para determinar a busca para um alimento "ideal" que pudesse substituir o leite materno $0^{6,25}$.

Várias descobertas contribuíram para melhorar a dieta das crianças. Devido aos altos índices de mortalidade infantil, por infecção e desnutrição, as "panadas" foram substituídas pela admi- nistração de leite não humano, como devaca, cabra, ovelha, mula e égua. 0 discurso em favor do leite animal foi fortalecido após ter sido divulgado, em 1838, que o leite de vaca continha mais proteínas do que o leite humano ${ }^{14}$. M amadeiras devidro foram patenteadas, na Europa enaAmé rica, e começaram a ser produzidas em larga escala. Em 1845, também foi patenteado, nos Estados Unidos, o primeiro bico de borracha (India rubber nipple) ${ }^{25}$. Naquela época, o Biberon nipple, feito de cortiça, ainda mantinha a popularidade, por não apresentar o cheiro e gosto ruins dos bicos escuros feitos de borracha vulcanizada ${ }^{12,14,25}$. Além da borracha e da cortiça, existiam bicos feitos de vários materiais, como estanho, prata, coral, marfim, vidro emadeira. Com o tempo, os bicos de borracha foram sendo aperfeiçoados e mudaram da cor preta para branca (que continha chumbo), depois para a vermelha e marrom, e deixaram de ter o gosto e o cheiro desagradáveis dos pioneiros. A despeito de tais avanços, as crianças continuavam a não sedesenvolver bem, apresentando quadros diarréicos, e os índices de mortalidade infantil eram altos ${ }^{12,14}$.

No final do século XIX e começo do século $X X$, existiam utensílios, feitos de vidro, em forma de banjo ou torpedo (Figura 4), conhecidos por apelidos como "Meu bichinho deestimação", "PríncipedeGales", "Princesinha" ou "Alexandra”.

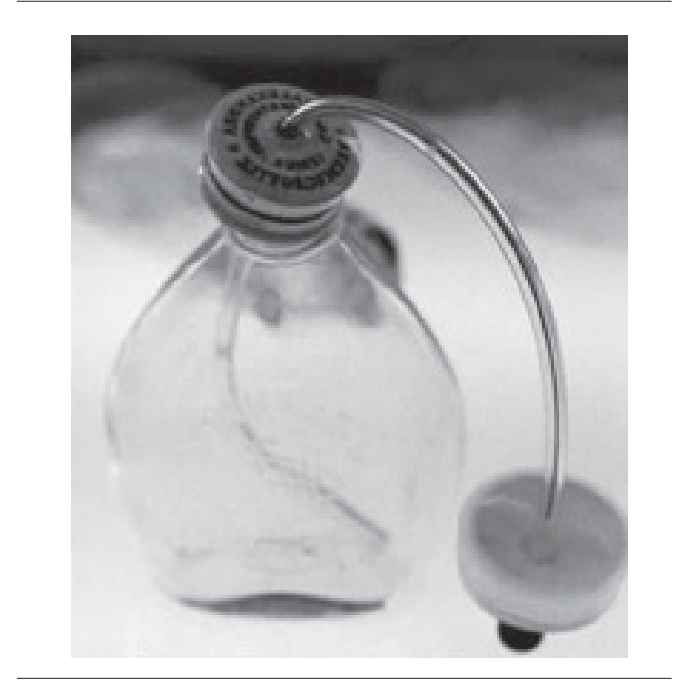

Figura 4. Alexandra Feeder; século XIX.

Fonte: http://www.pedialink.org/pedialink/neopix/ view.cfm?photol $\mathrm{D}=2182 \&$ topic $|\mathrm{D}=023 \&| \mathrm{v} \mid=2 \&$ myLevel $=\mid$ 
Adaptado à abertura superior existia um tubo de borracha que atingia o fundo da garrafa e terminava vários centímetros acima do gargalo, com um bico preto, adaptado em uma peça de 0sso. Estas mamadeiras foram lançadas no mercado, ressaltando-se a "vantagem de o bebê poder se alimentar sem a assistência da mãe", pois o canudo no interior permitia que a criança mamasse deitada ou sentada, sem a necessidade de segurar o objeto ${ }^{14,19,25}$. A impossibilidade de higienizar o utensílio de forma adequada, principalmente no interior do tubo, fez a mortalidade infantil atingir cifras assustadoras, uma vez que apenas duas em cada dez crianças atingiam a idade de dois anos, e os apelidos carinhosos foram dando lugar a outros como "Assassino" e "M atador". M esmo assim, o banjo continuou sendo comercializado até $1920^{14}$. Outra forma de mamadeira bastante difundida na época foram os "banana boats", planos na porção inferior e com duas aberturas, uma em cada ponta. Eles funcionavam como os "submarinos", sendo o fluxo de leite regulado pelo dedo adaptado em uma das pontas, enquanto a outra era colocada na boca da criança. Com o aparecimentos dos bicos de borracha, eles foram adaptados a uma das extremidades dos submarinos ${ }^{14}$.

No início do século passado, as mamadeiras assumiram forma cilíndrica cônica e, em 1950, a Pyrex ${ }^{\circledR}$ introduziu no mercado a "mamadeira de vidro resistente ao calor", que se adaptava aos esterilizadores. Estas mamadeiras tinham um bocal estreito, o qual era "vestido" pelo bico de borracha. A boca estreita dificultava a limpeza e por isso elas foram substituídas por outras de gargalo mais amplo ${ }^{14}$. Com o tempo, o bico passou a ser acoplado ao gargalo por uma peça de plástico rosqueada, que impedia que ele se desprendesse se a criança o puxasse.

0 vidro deu lugar ao plástico e os bicos de borracha, aos de silicone, mas a mamadeira, como a conhecemos hoje, éa mesma decem anos atrás. Algumas tentativas de inovar acabaram sendo uma repetição de erros do passado. Por volta de 1960, a Angel's $\varsigma^{\circledR}$ lançou no mercado um "novo" modelo de mamadeira, que tinha um canudinho adaptado ao bico e, por isso, "permitia à criança mamar sentada"14. 0 modelo era um "banjo" modernizado. Outra invenção foram as" M ix-onthe-go". Nessas mamadeiras, o leite em pó ficava separado da água e só se dissolvia na hora em que a mamadeira era entornada na boca da criança. Elas eram vendidas salientando-se a "vantagem de dispensar a refrigeração", pois "o leite era preparado no momento de ser ingerido" ${ }^{14}$.
Nota-se que houve pouca variação nos utensílios empregados desde os primórdios da história. Muitos deles reaparecem em momentos distantes, embora tenham sido substituídos devido ao aumento da mortalidade infantil, determinada em parte pela dificuldade de higienização.

Durante séculos, os alimentos administrados como alternativa à amamentação davam poucas chances de vida à criança, visto serem inadequados em termos nutricionais ou causarem doenças provocadas por contaminação 24,25.

A partir de meados do século XIX, começaram a ocorrer mudanças mais radicais em termos da alimentação infantil, quando Gail Borden descobriu, em 1856, um método deproduzir leite condensado, que era estéril e por isso passível de conservaçãa $0^{6,25,26}$. A descoberta do processo de pasteurização (1864) também contribuiu para queo leite pudesse ser transportado do campo para as cidades sem azedar; no entanto, muitos médicos se opuseram ao seu uso por acreditarem que provocava uma diminuição no valor nutricional do leite e esta só veio a ser empregada, de rotina, após $1915^{25}$. Pouco tempo depois (1883), M eyenberg descobriu como evaporar o leite de cabra, e M eigs (nos Estados Unidos) e Biedert (na Alemanha) desvendaram, concomitantemente (1885), a composição do leite materno, comprovando o baixo percentual de proteína quando comparado ao leite de vaca ${ }^{6}$. Difundiu-se, a partir deentão, a necessidade do leitede vaca ser diluído e acrescido de açúcar, para tornar sua composição mais parecida com o leite materno. A indústria passou a investir na produção de leites evaporados emodificados, na tentativa de conseguir um leite que se assemel hasse ao humano ${ }^{6}$. Fábricas foram abertas em várias partes do mundo à medida que o mercado se expandiu, principalmente após a Segunda Guerra (baby boom $)^{6}$.

Embora o leite materno seja o melhor alimento para o lactente, por ser espécie-específico, a amamentação, que já havia diminuído com a Revolução Industrial (a partir de meados do sé culo XVIII) e com a descoberta do processo de pasteurização do leite, esterilização de objetos, noções dehigieneer refrigeração (início do século $X X$ ), ficou ainda mais desestimulada com o desenvolvimento da indústria produtora de leites específicos, bicos e mamadeiras. ${ }^{16} 24$ Interesses mercadológicos e as estratégias da promoção comercial, muitas vezes divulgados como avanços científicos, acabaram por convencer a população de que o melhor alimento para ser dado às crianças eram as fórmulas lácteas ${ }^{6}$. Por mais de 
duas gerações, a amamentação ficou relegada a um segundo plano e teve ainda a contribuição do movimento feminista, que lutava pela emancipação da mulher ${ }^{3}$.

A partir de 1965, nos Estados Unidos ${ }^{24}$, e de 1970, no Brasil ${ }^{26}$, teve início um movimento em favor da retomada da amamentação, sendo, com o tempo, recomendada de forma exclusiva nos primeiros quatro meses e complementada, com outros alimentos, até um ano.

$\mathrm{Na}$ década de noventa, a Organização Mundial da Saúde (OM S), o Fundo das Nações Unidas para a Infância (UNICEF), a Organização Pan-Americana da Saúde (OPAS) e o M inistério da Saúde passaram a promover ações, no sentido de incentivar o aleitamento materno, proibindo a propaganda de leites artificiais, bicos, chupetas e mamadeiras ${ }^{6}$.

Desde 2003, a OM S recomenda que o aleitamento materno seja exclusivo até os seis mesese continuado com alimentação complementar até pelo menos os dois anos ${ }^{1}$.

Todos os benefícios nutricionais, imunológicos, emocionais e econômico-sociais do leite materno têm motivado campanhas em favor do aleitamento. Crianças amamentadas apresentam crescimento quedifere das alimentadas com leite não humano ou fórmulas, diminuindo a obesidadeinfantil esuas consequências futuras, como as doenças cardiovasculares e diabetes, e estão menos propensas a alergias, infecções respiratórias e gastrintestinais ${ }^{27-30}$. 0 vínculo mãe-filho fica fortalecido, dando condições à criança de se desenvolver emocionalmente, além de diminuir a incidência de câncer na mãe 5,24 .
Esforços têm sido feitos no sentido de evitar o desmame precoce, pelo confundimento de bicos, recomendando-se o uso do copo para alimentar prematuros ou crianças amamentadas ao seio cujas mães, voltando ao trabalho após a licença, passam períodos do dia longe de seus filhos. Howard et al. ${ }^{31}$ demonstraram que administração de suplementos no copo, para crianças amamentadas ao seio, é eficaz ${ }^{31}$, mas em muitas creches opta-se pelo uso da mamadeira, sob a al egação de que sua administração é mais rápida e eficiente. Dowling et al. ${ }^{33}$ publicaram, em 2002, um trabalho em que questionam a eficácia e a eficiência do copo devido às perdas determinadas por derramamento. 0 assunto permanece controverso.

A literatura também é consistente em afirmar que o uso de mamadeira acarreta consequências à saúde da criança ${ }^{34}$. Se anteriormente problemas com a contaminação do leitepodiam contraindicar a suplementação ou substituição do al eitamento, hoje novos prejuízos têm sido também relatados. Entre eles, aparecem as alterações da função respiratória, de deglutição, mastigação, fonação e dentição, devidas ao desenvolvimento craniofacial inadequado provocado pela sucção da mamadei ra, que difere da do seio ${ }^{35,36}$.

A pesar de todos os avanços científicos e tecnológicos no sentido de minimizar os problemas das crianças não amamentadas, continua sendo mais importante empenhar todos os esforços possíveis para que as mães amamentem seus fillhos de forma exclusiva até os seis meses e prolongada com alimentos complementares até pelo menos dois anos, como recomenda a OM S.

\section{Colaboradores}

SD Castilho trabalhou na concepção, pesquisa, redação do texto e preparação final do artigo. AA Barros Filho eM Cocetti trabal haram na concepção e redação final do artigo. 
1. WHO/UNICEF. Global strategy for infant and young child feeding. Geneva: World Health Organization; 2003.

2. Almeida JAG, Novak FR. Amamentação: um híbrido natureza-cultura. J. Pediatr. (Rio J.) 2004; 80(5): 119-125.

3. Tan KL. Breast feeding: social, economic and medical considerations. Ann Acad M ed Singapore 1983; 12(4):609-613.

4. Dunn PM. Sir Hans Sloane (1660-1753) and the value of breast milk. Arch Dis Child Fetal Neonatal Ed 2001; 85:F73-F74.

5. Ramos CV, Almeida JAG. Maternal allegations for weaning: qualitative study. J. Pediatr. (Rio J.) 2003; 79(5):385-390.

6. Rea MF. Substitutos do leite materno: passado e presente. Rev. Saude Publica 1990; 24(3):241-249.

7. International Society on Infant Studies Conference. 2000 - Birghton. Stone Age babies in a space age world: evidence-based evolutionary contributions to birth and development (Symposium). [site da Internet] [acessado $2007 \mathrm{dez} 3$ ]. Disponível em: http://www.isisweb.org/ICIS2000Program/ web_pages/group564.html

8. Wiseman TP. Remus: A Roman Myth. UK: Cambridge University Press; 1995.

9. Morford MPO, Lenardon RJ. Classical Mythology. $7^{\text {th }}$ ed. New York: Oxford University Press; 2003.

10. Middleton $C$, editor. A aurora da humanidade. $2^{\mathrm{a}} \mathrm{ed}$. Rio de Janeiro: Abril Livros Ltda; 1993.

11. Fildes VA. Breasts, bottles and babies: a history of infant feeding. Edinburgh: Edinburgh University Press; 1986.

12. Greenberg MH. Neonatal Feeding. In: Smith GF, Vidyasagar D. Historical Review and Recent Advances in Neonatal and Perinatal Medicine. Mead Johnson Nutritional Division, 1980 [site da Internet] [acessado $2007 \mathrm{dez} 3$ ]. Disponível em: http:// www.neonatology.org/classics/mj1980/ch04.html

13. Encyclopaedia Britannica. [site da Internet] [acessado 2007 dez 3]. Disponível em: http://www. britannica.com/eb/article/53658/writing

14. The history of the feeding bottle. Baby-bottle museum. [site da Internet] [acessado $2007 \mathrm{dez}$ 3]. Disponível em: http://www.babybottle-museum.co.uk/ articles.htm

15. Vinagre RD, Albuquerque Diniz EM, Costa Vaz FA. Human milk: a bit of history. Pediatria (São Paulo) 2001; 23(4):340-345.

16. Ben-Nun L. Breast-feeding: The roots. Minerva Pe diatr. 2006; 58(6):551-556.

17. Sociedade Bíblica do Brasil. A Bíblia Sagrada: antigo e novo testamento. Edição revista e atualizada. Rio de Janeiro: Sociedade Bíblica do Brasil; 1969.

18. Barber EW. The M ummies of U rumchi. New York: WW Norton \& Company. Inc.; 1999.

19. American Academy of Pediatrics. [site da Internet]. [acessado 2007 dez 3]. Disponível em: http://www. pedialink.org/pedialink/neopix/index2.cfm?my Level $=$ I

20. Gartner LM, Stone C. Two thousand years of medical advice on breastfeeding: comparison of Chinese and western texts. Semin Perinatol. 1994; 18(6):532-536.
21. Hawwas AW. Breast feeding as seen by Islam. Popul Sci. 1987; 7:55-58.

22. Durer, A. Madonna with a Siskin. 1506. Oil on panel. Staatliche Museen zu Berlin, Gemaldegalerie, Berlin, Germany. [site da Internet] [acessado 2007 dez 3]. Disponível em: http://www.abcgallery.com/ D/durer/durer65.html

23. Badinter E. U m amor conquistado - o mito do amor materno. 5a ed. Rio de Janeiro: Nova Fronteira; 1985.

24. Riordan J, Countryman BA. Basics of breastfeeding. Part I: Infant feeding patterns past and present. JOGN Nurs. 1980; 9(4):207-210.

25. Schuman AJ. A concise history of infant formula (twists and turns included). Contemporary Pediatrics [periódico na Internet] 2003 [acessado 2006 set 7];2:91:[cerca de 8 p.]. Disponível em: http:// www.contemporarypediatrics.com/contpeds/content/printContentPopup.jsp?id=11

26. Giugliani ERJ, Lamounier JA. Breastfeeding: a scientific contribution to the practice of health care providers. J. Pediatr. (Rio J.) 2004; 80(5):117-118.

27. Onis M, Garza C, Onyango AW, Borghi E. Comparison of WHO Child Growth Standards and CDC 2000 Growth Charts. J. N utr. 2007; 137(1):144-148.

28. Gdalevich $M$, Mimouni $D$, David M, Mimouni $M$. Breastfeeding and the onset of atopic dermatitis in childhood: a systematic review and meta-analysis of prospective studies. J Am Acad Dermatol. 2001; 45(4):520-527.

29. Gdalevich M, Mimouni D, Mimouni M. Breastfeeding and the risk of bronchial asthma in childhood: a systematic review with meta-analysis of prospective studies. J Pediatr. 2001; 139(2):261-266.

30. Victora CG, Smith PG, Vaughan PJ. Evidence for the protection by breast-feeding against infant death for infections diseases in Brazil. Lancet 1987; 2(8554):451-455.

31. Howard $C R$, Blieck EA, ten Hoopen $C B$, Howard FM, Lanphear Bp Lawrence RA. Physiologic Stability of newborns during cup and bottle feeding. $\mathrm{Pe}$ diatrics 1999; 104(5):1204-1207.

32. Kuehl J. Cup feeding the newborn: what you should know. J Perinat Neonatal N urs. 1997; 11(2):56-60.

33. Dowling DA, Meier PP, DiFiore JM, Blatz $M$, Martin RJ. Cup-feeding for preterm infants: mechanics and safety. J Hum Lact. 2002; 18(1):13-20.

34. Jelliffe $D B$, Jelliffe EF. The uniqueness of human milk: an overview. Am J Clin Nutr. 1971; 24(8):10131024.

35. Neiva FCB, Cattoni DM, Araújo Ramos JL, Issler $H$. Early weaning: implications to oral motor development. J. Pediatr. (Rio J.) 2003; 79(1):7-12.

36. Carrascoza KC, Possebon RF, Tomita LM, Alves de $M$ oraes $A B$. Consequences of bottle-feeding to oral facial development of initially breastfed children. J. Pediatr. (Rio J.) 2006; 82(5):395-397.

Artigo apresentado em 31/07/2007

Aprovado em 23/11/2007 